\title{
HISTORICAL CHARACTERISTICS OF EMIGRATION FROM RURAL JAPAN IN THE PRE-WORLD WAR II ERA
}

\section{Yoshio Kawamura}

Ryukoku Extension Center, Ryukoku University \& Kyoto Prefectural College of Agriculture E-mail: yoshiokawamura@hotmail.com

Citation: Kawamura, Y. 2017. Historical Characteristics of Emigration from Rural Japan in the Pre-World War II Era. J. Asian Rur. Stud. 1(2): 109-122

\begin{abstract}
Spatial mobility like rural-urban migration is an important social phenomenon to measure the degree of freedom and dynamism of a society that is directly related to industrialization. The same applies to spatial mobility of emigration, which is permanent or long-term transmigration from a nation to another nation. Compared with Europe after the Industrial Revolution where emigration was a major social mobility, Japanese emigration after the Meiji era until World War II, was an exceptional social mobility in its industrialization process. This paper aims to clarify the historical characteristics of Japanese emigration during the prewar period. Three approaches were introduced. The first was to extract periodicity from the trend of migration, finding four medium-term cycles with 15-20 years; shifting the destination from Hawaii, North America, South America and China; and changing their intensions from tentative emigration of contracted labor for remittance to permanent emigration for settlement of agricultural firm in the receiving country. The second is to clarify the Japanese government framework which created institutionalized marginality to the emigrants, causing a discrimination structure within the emigrants society. The third is to identify push and pull factors of Japanese emigrants, finding seven factors: natural environments and natural disasters, increasing population and surplus people, commercialized agricultural products and faded crops, poverty and income differences, accessibility to external society, value of performance orientation, and emigration encouraging agency. Although the situation of emigration is directly affected by the international relations around Japan as well as tense relations between the value and behavior of Japanese emigrants and those of the receiving society, emigration itself results from the personal initiative of an emigrant and thus its mechanism is complicated and diversified, requiring multidimensional framework of ordinary income opportunities in the sending community in which emigration is positioned as one of their income opportunities.
\end{abstract}

Keywords: Japanese rural emigrants; characteristics of emigration; periodicity of emigration; marginality of emigrants; pre-world war two 


\section{Introduction}

Mobility of human beings is an important social phenomenon that demonstrates the degree of freedom and dynamism of a society, or fluctuation of a society. Social mobility such as occupational mobility and stratificational mobility accompanies, in many cases, spatial mobility, which is a movement from a certain place to another place. The typical form of the spatial mobility is rural-urban migration: movement primarily from rural areas to urban areas. Many such movements simultaneously accompany occupational mobility from the agricultural to non-agricultural sectors of production and stratificational mobility from the farmer or peasant stratum to the worker stratum. The majority of these movements could be social phenomena induced by changing industrial structures, mainly as a consequence of industrialization.

The same applies to spatial mobility designated as emigration or immigration, which means permanent or considerably long-term transmigration from a certain nation to another nation. In Europe, after the Industrial Revolution, emigration became an important social phenomenon. The number of emigrants from Europe to the "New World" during about one and a half centuries from the beginning of the 19th century to World War II reached as many as 60 million people; it is assumed that about one-third were from Britain and about one-sixth from Italy. Therefore, people corresponding to about three-fourths of the population growth in that period in Britain emigrated and people corresponding to about one-half of population growth in that period in Italy emigrated. Consequently, for Britain, people corresponding to about one-third of the mother country population and for Italy, people corresponding to about one-fifth of the mother country population are now living overseas as British and Italian immigrants, primarily in North America and South America, where societies mainly comprise immigrants.

In contrast, in Japan, the people who emigrated to Hawaii, North America, South America, China, and other Asian regions from the Meiji era to World War II are estimated as about one million at most corresponding to only one percent of the national population (Ishikawa, 1969); it might be said that the emigrants were exceptional as an illustration of labor force mobility. This paper aims to clarify how this exceptional labor mobility, Japanese migration, is characterized in the process of its history during the prewar period. For this aim, three approaches are introduced. The first is to extract the periodicity in the trend of migration, finding whether or not cycles of emigration exists; whether or not the cycles of emigration are related to changes in the destination; and whether or not those changes are associated with changes in their intensions of emigration. The second is to clarify the Japanese government framework to Japanese emigrants which determined the nature of emigrants society. The third is to identify external and internal factors of Japanese emigration but introducing the push-pull hypothesis. 


\section{Periodicity of Japanese Emigrants}

Substantial emigration from Japan began in the Meiji era after the isolation from other nations that had continued for as long as 300 years, specifically in the latter half of the Meiji era, after the so-called Industrial Revolution. Table 1 presents an estimation of the number of people who emigrated overseas during one century since Meiji Restoration as about 900 thousand. Of those, emigrants after World War II (WWII) were fewer than 20\%; the majority emigrated up to the first half of the 1960s. In other words, Japan was confronted with serious population and food shortage problems for several years following WWII because people repatriated from overseas reached greater than 6 million and the natural increase in the population which took place suddenly in addition to reduction of national boundaries and devastation of industries after defeat in war. In light of such social circumstances, overseas emigration became active again in the 1950s: emigration exceeded 10 thousand per year from 1955. However, concomitantly with shortages of labor that arose because of economic growth in the 1960s, the number of overseas emigrants decreased gradually: fewer than 5,000 people emigrated annually after 1965 .

Table 1. Number of Japanese Overseas Emigrants

\begin{tabular}{|c|c|c|c|c|c|c|}
\hline \multirow{2}{*}{ Destination } & \multicolumn{2}{|c|}{ Pre-war } & \multicolumn{2}{|c|}{ Postwar } & \multicolumn{2}{|c|}{ Total } \\
\hline & People & $\%$ & People & $\%$ & People & $\%$ \\
\hline North America (excl. Mexico) $)^{1)}$ & 411,409 & 55 & 86,892 & 54 & 498,301 & 55 \\
\hline Central and South America (and Mexico) & 244,536 & 33 & 70,002 & 44 & 314,558 & 35 \\
\hline Others $^{2)}$ & 88,176 & 12 & 4,007 & 2 & 92,183 & 10 \\
\hline Total & 744,120 & 100 & 160,921 & 100 & 905,041 & 100 \\
\hline
\end{tabular}

Notes: 1) Including Hawaii. 2) Excluding continental China, Korea peninsula, Taiwan. 3) Excluding emigrants from Okinawa.

Source: Table I-1 and Table III-1, Consular and Migration Affairs Department, Ministry of Foreign Affairs, Overseas Development of Japanese Citizens: Progress in 100 Years of Emigration (Data Version), 1971, pp. 2-3, 137.

Therefore, most Japanese emigrants are those who moved overseas before the war: slightly more than one-half emigrated to North America, primarily to the United States of America, and a third emigrated to South American nations, primarily Brazil. The yearly trends of the number of these overseas emigrants are presented in Fig. 1, from which it is known that the variation of the number of overseas emigrants in the prewar period shows a gradual increase in the long run. This trend consists of four medium-term cyclic variations, each of 15-20 years. Each cycle involves short-term cyclic variations of about six years. Moreover, these medium-term cyclic variations show time divisions by trends that are characteristic to prewar emigrants.

In the first cycle, which is the second half of the Meiji era from 1885 (Meiji 18) to 1908 (Meiji 41), it is characteristic that most emigrants moved to Hawaii and North America, although the number of emigrants to Hawaii is far greater than to North 
America every year. One exception is the emigration trend in 1900 (Meiji 33) which is the year after indentured emigration to Hawaii was prohibited. The first half of the first period is the so-called governmental contract emigration era, when emigration was determined based on the "Japan-Hawaii Travel Treaty" concluded in 1886 (Meiji 19) between the Japanese government and the Hawaii government, which continued until the outbreak of the Sino-Japanese War in 1894 (Meiji 27). During this period, most emigration to places other than Hawaii and after the governmental contract was performed in the form of private contract emigration by private brokers such as emigration firms. However, because of racial anxiety, the so-called Yellow Peril in North America after the Russo-Japanese War, emigration of Japanese people to Hawaii and the continental U.S. was prohibited in 1907 (Meiji 40). Furthermore, migration to North America was sharply limited by the "Japan-US Gentlemen's Agreement" and the "Lemieux Protocol" concluded with Canada.

The second period is mainly in the Taisho era from around 1909 (Meiji 42) to around 1924 (Taisho 13). Characteristically during this period, the mainstream of emigration is directed to two regions: Hawaii and North America, and South America. Even under enforcement of migration restrictions by North American countries, about two-thirds of all emigrants in this period were accounted for by emigrants to Hawaii and North America because re-entry of the emigrants and calling of wives and children of foreign residents were permitted. However, in contrast to the first period, the number of emigrants to North America since 1913 (Taisho 2) tended to be greater than those to Hawaii. As the flow of emigrants to the mainland US increased, anti-Japanese campaigns gradually became violent in California, where about three-fourths of Japanese residents resided on the mainland. Then, by the "Land Law for Foreigners" established in 1913 (Taisho 2) and "New Land Law for Foreigners" in 1921 (Taisho 10), prohibition of real property possession by Japanese, who were not substantially allowed to become naturalized citizens by "New naturalization law" in 1906 (Meiji 39), was attempted, thereby markedly inhibiting development of Japanese immigrants in the agricultural sector. This movement engendered the establishment of "New Immigration Law" in 1924 (Taisho 13), which rendered emigration of Japanese into the United States of America almost impossible.

In the meantime, fewer than one-fourth of all emigrants in the second period emigrated to Latin American; the majority of them to South America, and substantial emigration ensued after 1908 (Meiji 41), when emigration restrictions to North American nations were enforced. Up to that time, emigration to Central America was active, concentrated emigration to Mexico took place for several years at the beginning of the 1900s (second half of Meiji 30s), but the majority of cases were inferred to have been migrants to the United States of America, and emigration to Central America remained on a small scale thereafter. Organized emigration to South America started in 
1898 (Meiji 31) by contract emigration to Peru, although yearly emigration to that continent took place after 1906 (Meiji 39). However, immigration treaties and contracts were concluded between the Sao Paulo state government, Brazil, and Japanese emigrant companies in 1908 (Meiji 41), the number of emigrants to Brazil greatly exceeded those to Peru after 1912 (Taisho 1). Consequently, emigrants to Brazil in the second period accounted for $2 / 3$ of all emigrants to South America.

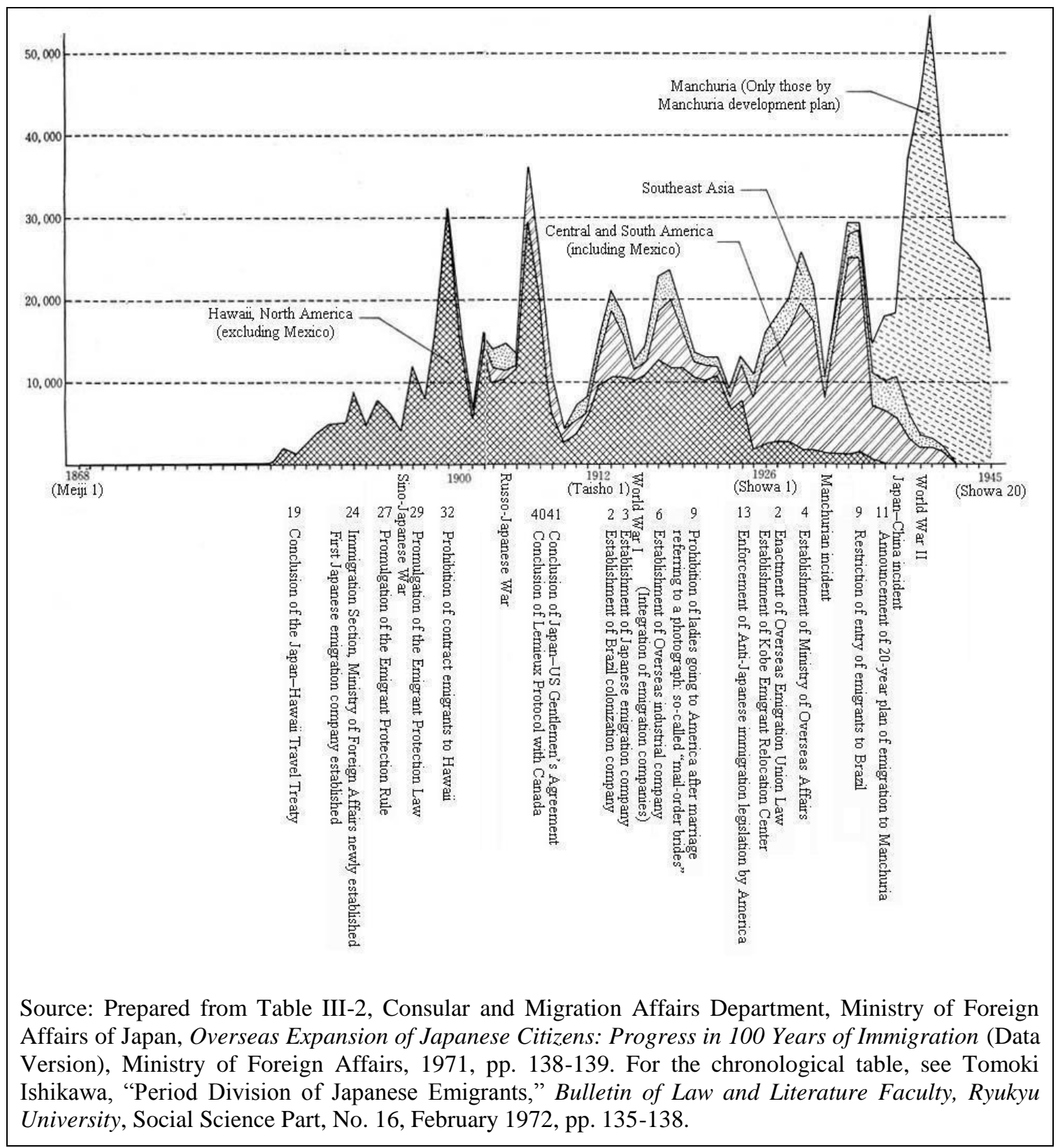

Figure 1. Transition of Japanese Oversea Emigrants (1868-1945) 
The third period was from around 1925 (Taisho 14) to around 1937 (Showa 12), the so-called Showa prewar period. It is characteristic that trends of the emigrants are dominated by emigrants to South America. The number of emigrants to North America decreased sharply because of the enforcement of the "New Immigration Law" of the United States of America; emigration to that continent became zero from 1936 (Showa 11). Meanwhile, the number of emigrants to South America showed an escalating tendency, irrespective of abolition of the contract emigration to Peru in 1923 (Taisho 12) and movements toward immigration restrictions in Brazil. Particularly, concentration of immigrants to Brazil, where creation of large-scale settlements was promoted by the Japanese emigration union, was remarkable; 90\% of emigrants to South America during this period were to Brazil. However, emigration to South America was virtually eliminated by Brazil's new constitution adopted in 1934 (Showa 9) and an immigration restriction law in Peru in 1936 (Showa 11). These events terminated the era of contract emigration and free emigration based on the consent of partner countries.

Since then, Japanese overseas emigration marked qualitative abrupt change, forming the fourth and final period of emigration in the pre-war period. Japanese emigration was developed primarily by Manchurian expansion based on an expansion policy to China. Therefore, the emigration was developed towards emigration with an extremely strong invasive nature. Eventually, those who emigrated during the decade preceding the war were repatriated from overseas after defeat.

\section{Institutionalized Marginality of Japanese Emigrants}

Ethnic Japanese who emigrated overseas as contract emigrants and free emigrants, and their second and third generation descendants were estimated as about 1.75 million as of 1980. A breakdown of this figure shows about $40 \%$ in North America, consisting of the United States of America and Canada, with fewer than 1\% to Central America, primarily Mexico, and about 60\% in South American countries including Brazil, where more than about 600 thousand immigrants reside. However, the number of ethnic Japanese living outside the country mainly in North America and Latin America are as few as only $1 \%$ of total population of Japan. This figure is extremely low compared with European country cases and reflects not only Japanese characteristics of the emigrants, but also features of Japanese social structure and modernization processes. In other words, it could be said that the modernization of Japan was accomplished in geographical conditions under which Japan is an island and thus isolated country and under historical conditions without undergoing external impact that was sufficiently strong to drastically change social circumstances and without the possibility of economic growth through colonialism, as occurred in the "New World" in the case of European countries. 
As a European example, in Britain in the 19th century, a sudden increase in the population caused enlargement of the enclosures in the agricultural sector, improvement of labor means and progress of industrialization in non-agricultural sectors, and excess population remained not only in farmer villages, but also in urban cities, which cultivated the background of immigration (Johnson, 1966). In fact, emigration projects in Britain were in many cases performed systematically by public institutions and charitable organizations as relief measures for large quantities of unemployed and poor people in urban cities and farm villages. At the same time, it is considered that emigrants had a strong "settlement" intention in a place to live from the beginning. In contrast, Japanese society in The Meiji era was more stable than British society: changes took place in a more gradual manner economically and socially. It might be said that excess population might be absorbed within the framework of domestic development of Japanese economy. Accordingly, encouragement of emigration at that time from Japan had such aspects as economic effects brought by money transfer from emigrants was considered important and emigrants themselves had a strong intention of being "guest laborers" (Ohkawa, 1974) from the beginning and wished to return home after a certain period (Fleming, 1979).

Generally, it was after the beginning of the Taisho Era, particularly during the latter half that Japanese emigrants tended to have strong intentions of settlement. As a background, there were such social circumstances that the domestic economy underwent recessions after entering the Taisho era, and hardships in rural areas were extremely serious. Increased population could not be absorbed within the framework of domestic economic development. Recessions in rural areas in 1913 (Taisho 2), rice riots in 1918 (Taisho 7), and a stock panic in 1920 (Taisho 9) preceded long recessions triggered by heavy declines of rice prices. Soon thereafter, escalation of recessions by the Great Kanto Earthquake in 1923 (Taisho 12) and a world crisis originating in banking crises in and after 1927 (Showa 2) occurred successively. The unemployment rate in urban cities reached a high level. About one-third of those who lost work each year returned to rural areas. In light of these circumstances, the Japanese Government launched overseas emigration promotion plans from a social policy standpoint. Subsidies were granted to overseas industrial companies: unified organizations of emigrant companies started lending to immigrants to Brazil in 1923 (Taisho 12). The government paid all travel expenses of emigrants to Brazil and commission charges of emigration companies in 1925 (Taisho 14), and also established the Kobe emigrant relocation center. The government established the "Overseas Immigration Union Law" in 1927 (Showa 2), with establishment of the Colonization Ministry in 1929 (Showa 4). Thereby a series of positive measures were taken.

Although it is apparent that the severe recession and overseas emigration encouragement policy by the government acted as strong factors for those who desired 
overseas emigration to have settlement intentions, it is considered that this trend was strengthened by agricultural colonization projects by an emigration union in Brazil. Creation of agricultural colonization in Brazil by Japanese was started by 2,000 Japanese families in the form of development of 50,000 tsubo (3.3 ha) land owned by Sao Paulo state, which was performed by a Brazil colonization company at the beginning of the Taisho era. Thereafter, settlements formed by small groups of 10-70 families developed at various locations in Sao Paulo state, whereas the creation of large-scale settler's land started by the "Alianza Plantation" promoted by the Shinano Overseas Association in 1924 (Taisho 13). Following this movement, similar development projects were promoted by Tottori, Toyama, and Kumamoto prefectures. Moreover, establishment of Overseas Immigration Union Joint Association in 1927 (Showa 2) accelerated the creation of large-scale settlements in Palana state and the Amazon region as well as Sao Paulo state. Those emigrants aiming at such colonization differed from the emigrants who emigrated for the sake of labor alone: the emigrants themselves prepared from the beginning for engagement in agricultural development projects on the premise of lifetime land possession. They accepted long-term economic risks and that the host nation would accept them from the beginning as normal constituent members in their respective societies. The majority of emigrants to Hawaii and North America in The Meiji era went there as workers in agriculture, fishery, forestry, and as household laborers. Similarly, at the beginning of emigration to Brazil, almost all emigrants went there to work as colono (contract workers in agricultural firms) and were then distributed to coffee plantations.

It is considered that overseas emigrants in the first half of the pre-war era intended for labor to become an important background for definition of concepts of emigrants in Japan. The "Emigrant Protection Rule" in 1894 (Meiji 27), which is the first regulation covering emigrants and "Emigrant protection law", which is a revision of the former in 1896 (Meiji 29) define emigrants as those going overseas for the purpose of labor: the "Emigrant Protection Law", finally revised to cope with annexation of Korea in 1907 (Meiji 40), states that "emigrants, as defined for this law are those leaving for foreign nations, except for China and Korea, for the purpose of engaging in labor, accompanied by their families to their location" and the types of labor are specified separately to be those related to agriculture, fishery, mining, industry, civil engineering, transportation, construction, cooking, laundry, sewing, barbers, waiters, and nursing (Funahashi, 1981). According to this law, overseas travelers with labor purposes were defined as "Emigrants" and were distinguished from "Non-emigrants" such as government clerks, merchants, students, travelers, or the like. Differentiation of this administrative procedure was specified in all official documents issued even after emigration as well as passports; it was observed until the 1920s. This differentiation assured formation of a discriminatory concept against immigrants in the pre-war period. In fact, it is pointed 
out that "Non-emigrant" passports were issued to "Emigrants" with property and status (Tsuruya, 1979).

At the same time, administrative differentiation between "Emigrants" and "Non-emigrants" served as an important factor for creation of discriminatory structures in the social world of overseas emigrants. Discriminatory sentiments arose such that those of a lower social position with high economic poverty who had no choice but to go abroad as migrant workers were classified to "Emigrants" and others as "Non-emigrants"; both were ranked in a socially hierarchical relation. In addition, such a general circumstance existed that receiving countries such as the United States of America were more generous to "Non-emigrants" than "Emigrants". For this reason, unscrupulous practices to obtain rights and interests in exchange from transfer from "Emigrant" to "Non-emigrant" status occurred between local Japanese liaison offices who were acting for consulate work and overseas emigrants. The important point is that such a discriminatory relation between overseas emigrants results from administrative differentiation by the Japanese government rather than by administrative differentiation by the receiving country. In other words, the Japanese government, who was in a position to protect all overseas emigrants equally, allowed domestic discriminatory views to be applied without alteration to the society of overseas emigrants.

\section{Push-Pull Hypotheses of Japanese Emigration}

Emigration can be regarded as one form of labor force mobility irrespective of the intention to become a migrant worker or settler; it might be said to be the most extreme form of mobility. Therefore, as a framework of emigrant analysis, the "Push-Pull Hypothesis" (Thomas, 1941; Anderson, 1956; Fuguitt, 1959), which has been discussed in research of labor force mobility, has a good validity for applicability. This hypothesis, based on the understanding that labor force mobility is attributable to socioeconomic differences between areas, emphasizing clarification of push factors for labor force mobility in the out-migration regions and pull factors in the in-migration regions. In other words, labor force mobility is grasped as an eventual phenomenon of regional differences of employment opportunity structures, and research efforts are concentrated on analysis of these regional fluctuations from both aspects of labor force supply and demand. Therefore, for analyses of emigration based on the premise of the "push-pull hypothesis", analyses of the home community of the emigrants (out-labor force) and analysis of the immigrant-receiving community (in-labor force) such as that of the United States of America, are required. Consequently, emigration is understood to be attributable to socioeconomic differences of these two communities.

However, it is also true that emigrants have special characteristics that distinguish them from other laborers. The first special characteristic is that of the immigrant-receiving side (pull-side), the labor force receiving side. Socioeconomic 
differences between labor forces outside and inside the country are usually extremely large compared with the domestic labor force mobility case. Moreover, many qualitative differences usually exist. Immigrant groups holding cultural and social characteristics of the mother country routinely generate various multilaterally tense relations with the immigrant receiving society, and transformations of both parties occur around these tense relations. Tolerance and exclusivity by the receiving side for outside groups pose problems. For example, the Yellow Peril hysteria in North America after the Russo-Japanese War, and anti-Japanese movements as represented by enforcement of the "Foreigners Land Law" in California in the 1910s are results of development of these tense relations from a daily life level to political and social problems. Therefore, for analysis of Japanese-American immigrants in the U.S., attention must be devoted to tense relations between the sense of value of Japanese emigrants and their behavior patterns based on them and those of American society (immigrant receiving side). The transformations of both parties should be understood in light of these tense relations.

The second special characteristic relating to the emigrants as the form of labor force mobility relates to the degree of freedom of movement from the push side to the pull side. This degree of freedom is influenced directly by interests between the emigrant-sending nation and the receiving nation. For example, the trends of Japanese emigration to the United States of America have been governed directly by foreign policies of Japanese and US governments corresponding to contemporary domestic situations in those countries, as represented by conclusion of the "Japan-Hawaii Travel Treaty" between the Japanese government and Hawaii government in 1886 (Meiji 19), prohibition of emigration to Hawaii by emigrant companies by the Japanese government in 1899 (Meiji 32), and recommencement of free emigration to Hawaii in 1901 (Meiji 34), conclusion of "Gentlemen's Agreement" between Japanese and US governments in 1908 (Meiji 41), prohibition of ladies going to America for marriage after referring to a photograph (so-called mail order brides) by the Japanese government in 1920 (Taisho 9), and enforcement of anti-Japanese immigration legislation by the US government in 1924 (Taisho 13). Therefore, for good understanding of trends of emigrants from Japan, it is indispensable to rank emigrants within the framework of international relations around Japan. In the meantime, if emigration is viewed from the push side, similarly to domestic labor force mobility, there are such special characteristics for emigrants themselves: accessibility to the place of emigration is low; information about the emigration destination is only slightly available; uncertainty is high because emigration to outside societies is based on long-distance travel; and movement costs in a broad sense are high.

Notwithstanding these special characteristics, many studies of emigration show that factors for emigrants are similar to outflow factors in domestic labor force mobility. For example, a study of emigrants from Britain since 19th century mentions, as 
important factors for emigrants, six items of population growth from the beginning of 19th century. Intermittent recessions in the agricultural sector occurred, along with intermittent introduction of labor saving technologies, famine in Ireland, fiercer competition in foreign markets, and organizational encouragement of emigration, together with expectations based on employment in the emigration destination, the possibility of agricultural development and free civil life. However, these six factors are those already considered as primary factors for labor force mobility from rural areas to urban areas in Britain in the same era. Moreover, it might be said that studies of Japanese emigrants show similar results. Based on these study results, major views about factors for emigrants might be summarized in the following seven items (Wakatsuki, 1979; Ishikawa; 1975).

\subsection{Natural environment and natural disasters}

This point of view emphasizes the relation between natural conditions and economical conditions with the understanding that many emigrants move from regions with little flatland or cultivated acreage, regions where soil is poor and agricultural production power is low, or regions where living conditions had been degraded by natural disasters, or some combination of these disadvantages.

\subsection{Increased population and surplus population}

This point of view emphasizes the mutual relation between population variation and economic conditions with the observation that emigrants are produced in regions or periods in which various economic conditions deteriorate because of increased population in a region or area; alternatively or concurrently, surplus population for an appropriate labor force results from introduction of labor-saving technologies.

\subsection{Commercialization of agricultural products and faded crops}

This point of view emphasizes that in a region and area where the yields of commercialized crops in agricultural production are high, hierarchical differentiation of farm families is promoted as the money economy promulgates, generating a social layer of economic poverty and surplus labor force in the agricultural sector which becomes a cause of emigration. It is further considered that when commercial crops tend to fade away because of the external economy, such economical distortions are further deepened, thereby accelerating the appearance of emigrants.

\subsection{Poverty and income differences}

It is common to mention the degree of economic hardship as a fundamental factor for emigrants, and the standpoint of the above-described three items is associated with the degree of economic hardship. Here, the degree of economic hardship means poverty 
based on the recognition that instead of indicating a lower economic level itself, the realized economic level is merely lower than the conventional economic level because of natural disasters, population growth and variation of external economy, or an income difference recognized from comparison with economically advanced regions, even if the conventional economical level is attained.

\subsection{Accessibility to external society}

This perspective considers that an open-minded advanced region where intercommunications with external societies take place frequently, more emigrants are produced rather than in self-sufficient, closed, lesser-developed regions. Although exchange with external societies is specified by developments of transportation modes and information access, this is a prior condition not only for recognition of commercialization of agricultural production and income differences, but also for acquisition of knowledge about overseas countries and emigration.

\subsection{Sense of value of performance orientation}

This perspective seeks factors for emigrants in a sense of value specifying social action of human beings. In general, a sense of value in association with social mobility is explained from an achievement principle and ascription principle (Kitagawa, 1983). The former means a case in which the target is accomplished by one's own willingness or efforts by capability to acquire from a certain social position another social position. The latter means a case in which the target is accomplished by social power of influences by inherent social standing such as ancestry and status and by social standing such as educational record and type of occupation acquired after birth. This perspective especially addresses the point that, as a factor for emigration, the emigrant holds a strong sense of value placing importance on the achievement principle. This standpoint includes a perspective by which many emigrants are produced from regions where people are enterprising. Their nature might be cultivated by a tradition as a maritime people and a tradition of migrant work. Many immigrants might come from regions where people have a strong resignation spirit, as typically seen with "Aki believers" of Jyodo-shinshu, who do not question a place to die and are strongly and spiritually affected by religion, as with a strict labor ethic.

\subsection{Presence of emigration encouraging agency}

This perspective embraces the importance of roles fulfilled by some emigration encouraging agency: those who encourage emigration underpin the production of emigrants. Although it is evident that emigrants show a tendency to be influenced directly by foreign policies of a government, establishment of various ordinances relating to the emigrants and execution of subsidization measures, establishment of 
overseas migration aid agencies, roles fulfilled by emigration-handling people (emigrant companies, emigration unions, etc.) at the emigration execution stage are considerable. This view also underscores activities by politicians and business leaders, who insist upon emigration encouragement from a sociopolitical viewpoint, behind these emigration encouraging agencies, and regions with stronger ties with them produce many emigrants.

\section{Conclusion}

Although the situation of emigration is directly affected by the international relations around Japan as well as tense relations between the value and behavior of Japanese emigrants and those of the receiving society, emigration itself results from the personal initiative of an emigrant. Thus, as is true of other forms of labor force mobility, its mechanism is extremely complicated and diversified. Therefore, each factor described above can justify only a part of the whole explanation of the mechanism of emigrants and each seems insufficient to explain reasons that are applicable to all aspects. Rather, it is realistic to consider that these factors acting upon each other in a sophisticated fashion. A researcher studying emigrants concludes that "at the very least, no sufficient explanation is possible for the fact that a factor explaining why many immigrants come from a certain region is not applicable to other regions under the same conditions." This point might be crucially important. Future themes will be construction of a hypothetical framework based on multidimensional composite action with emigrants ranked under association with other ordinary job opportunities.

\section{References}

Anderson, Theodore, "Inter-metropolitan Migration: A Correlation Analysis," American Journal of Sociology, LXI, March 1956.

Fuguitt, Glenn V., "Part-time Farming and the Push-Pull Hypothesis," American Journal of Sociology, LXIV No. 4, January 1959.

Funahashi, Kazuo, "Towards Site Survey of Villages Produced Immigrants," Bulletin of Social Science Research Institute, Ryukoku University, No. 12, 1981.

Government of Japan, Ministry of Foreign Affairs, Recent Status of Japanese Foreign Diplomacy, 1981.

Government of Japan, Ministry of Foreign Affairs, Overseas Expansion of Japanese Citizens: Progress in 100 Years of Immigration (Main Text), 1971.

Government of Japan, Ministry of Foreign Affairs, Overseas Expansion of Japanese Citizens: Progress in 100 Years of Immigration (Data Version), 1971.

Ishikawa, Tomoki, "Japanese Emigrants Viewed from Statistics: First Report", Chiri-Kagaku, No. 11, 1969.

Ishikawa, Tomoki, "Emigrants/Immigrants from Setouchi Area," Historical Science, No. 126, 1975.

Johnson, Stanly C, A History of Emigration: From the United Kingdom to North America, 1763-1912, London: Frank Cass, 1966. 
Kawamura, Yoshio, "Assumption for Analysis Relating to Socio-economic Structure of the Colony Produced Emigrants and Its Mechanism," Bulletin of Social Science Research Institute, Ryukoku University, Vol. 12, 1981.

Miyagawa,Minoru, "Social mobility" in Ryukichi Kitagawa (ed.), Dictionary of Modern Sociology, Yushindo, 1983.

Ohkawa, Kenji, "Introduction to Transition of Labor by Occupations and Regions in Japan" by pre-war Ninnosuke Nakajima (Shakaiseisaku-jiho, No. 199).

Ohkawa, Kenji, Economy of Migrant Workers, Kinokuniya Shoten, 1974.

Thomas, Dorothy S., Social and Economic Aspects of Swedish Population Movement, New York: MacMillan, 1941.

Tsuruya, Jyu, "Immigrants and Non-immigrants," Rekishi Koron, Vol. 5, No. 1, 1979.

Wakatsuki, Yasuo, "Japanese Emigration to the United States, 1866-1924: A Monograph," in Donald Fleming (ed.), Perspectives in American History, (Vol. XII) Boston: The Charles Warren Center for Studies in American History, Harvard University, 1979.

Wakatsuki, Yasuo, "Japanese Emigration", "Factor Analysis of Regions Produced Many Immigrants to America”, Research Paper, Agricultural Department of Tamagawa University, No. 19, 1979. 